\title{
O Programa de Educação Profissional de Minas Gerais e a evasão escolar: um estudo preliminar (2008-2010)
}

\author{
Wander Augusto Silva ${ }^{1}$ \\ wander.silva@uemg.br \\ Rosemary Dore ${ }^{2}$ \\ rosemary.dore@pq.cnpq.br
}

\begin{abstract}
Resumo
Este estudo apresenta um breve histórico das políticas públicas educacionais adotadas pelo governo do Estado de Minas Gerais, nas últimas décadas, para o ensino profissionalizante. Tenta-se definir e identificar a questão do abandono escolar no sentido de entender melhor esse fenômeno educacional. Posteriormente, é estudado o Programa de Educação Profissionalizante de Minas Gerais (PEP/MG) instituído pelo governo desse estado em 2007, que oferece, gratuitamente, vagas aos estudantes mineiros que desejam realizar cursos técnicos e estejam cursando ou tenham terminado o ensino médio. Para oferecer os cursos do PEP-MG, o estado compra vagas em escolas privadas e as disponibiliza aos estudantes aprovados em exame de seleção organizado pelo próprio estado. O estudo aqui apresentado resulta de uma análise preliminar relativa ao PEP I, primeiro ano do programa, realizado em 2008. Em seguida, mostra-se, com base em dados estatísticos, a evasão ocorrida no PEP I, indicando seus principais motivos.
\end{abstract}

Palavras-Chave: ensino médio; ensino profissionalizante; evasão escolar.

1 Professor da Faculdade de Educação da Universidade do Estado de Minas Gerais (FaE/CBH/UEMG). Doutorando em Educação pela FaE/UFMG.

2 Professora-doutora do Programa de Pós-Graduação da Faculdade de Educação da Universidade Federal de Minas Gerais (FaE/UFMG). 


\section{Introdução}

Este trabalho é um estudo preliminar sobre o Programa de Educação Profissional (PEP), política educacional do governo do Estado de Minas Gerais instituída a partir do ano de 2007. O presente texto focaliza, brevemente, as políticas adotadas pelo governo mineiro com referência à formação profissional de nível médio, entre 1996 e 2007: primeiramente, o governo extinguiu a formação profissional nas escolas de nível médio do estado, em 1996, e, dez anos depois, por meio da política do PEP, passou a comprar vagas na rede privada para oferecê-las aos estudantes que desejam uma formação técnico-profissional. Trata-se de uma clara tendência à privatização da formação de técnicos de nível médio, ocorrida no Estado de Minas Gerais. Além disso, mesmo que muitos estudantes recebam gratuitamente vagas em escolas privadas para seguir sua formação técnica, é muito alto o índice de abandono verificado no PEP-MG. Esse é o problema que este estudo procura evidenciar.

\section{$2 \mathrm{O}$ ensino profissionalizante em Minas Gerais: 1995-2010}

Nos primeiros anos da década de 1990, acentuou-se no Brasil a tendência à privatização da educação, com a retirada do Estado como agente financiador de políticas públicas na área social, atingindo, particularmente, a educação e a cultura.

O Estado de Minas Gerais, à época governado por Eduardo Azeredo, seguia de perto e acolhia a política de minimização do Estado na área social. Em 1995, o governo mineiro celebrou com o Banco Mundial um contrato de empréstimo para financiamento do "Projeto de Melhoria da Qualidade na Educação Básica" e, ao mesmo tempo, iniciou a elaboração do "Programa de Melhoria do Ensino Médio" (PIRES, 2002). O intuito principal dessa medida foi o de solucionar o problema de vagas na educação média, então considerado meta principal a ser atingida pelo governo Azeredo (DORE SOARES, 1999). A proposta a ser implementada 
tinha como objetivo ampliar o ensino médio com formação propedêutica e estabelecer parcerias com os setores produtivos e de serviços para oferecer cursos técnicos. Esse modelo implicava a extinção dos cursos profissionalizantes, então existentes nas escolas estaduais. Essas suprimiriam os seus cursos técnicos ${ }^{3}$, os quais seriam organizados pelo Estado em parceria com o setor privado, tais como organizações sociais, instituições particulares, instituições ou empresas governamentais.

Em 1996, o governo de Minas Gerais estabeleceu que, até 1998, as habilitações profissionais ofertadas pelas escolas da rede estadual seriam avaliadas e, dependendo do resultado da avaliação, seriam extintas ${ }^{4}$. Como resultado dessa medida, foram eliminadas 311 habilitações profissionais das instituições escolares da rede estadual (PIRES, 2002).

A consequente redução da oferta de formação profissional pelas escolas estaduais, resultante da reforma empreendida pelo governo do Estado de Minas Gerais, atendia, segundo Dore Soares (1999), às recomendações do Banco Mundial, que se transformou na principal agência de assistência técnica em matéria de educação para os países em desenvolvimento. Ainda conforme a autora, as políticas adotadas pelo Banco Mundial vinculavamse às determinações advindas do "Consenso de Washington".

O elo entre as políticas educacionais no Brasil e as diretivas do Banco Mundial também é analisado por Cunha (2000). Para ele, desde o início da década de 1990, aquele banco fazia recomendações explícitas a respeito da educação técnico-profissional, entendida como um elemento estratégico de mudança da estrutura educacional de diversos países, especialmente dos da América Latina.

Cunha (2000) menciona o documento "Educación técnica y formación profesional" para dele destacar o propósito de separar a educação e a capacitação profissional, com base no argumento de que cada uma delas demanda aspectos diferentes dos sistemas, das instituições,

3 Conforme Pires (2002), a Escola Estadual Técnica Industrial Professor Fontes, em Belo Horizonte, em 1998 esteve obrigada pela Secretaria de Estado de Educação de Minas Gerais (SEE/MG) a encerrar os cursos técnicos de nível médio. A comunidade dessa escola, através de forte mobilização, pediu a continuidade dos cursos técnicos, que foram reativados em 1999 (curso de Técnico em Mecânica e Técnico em Eletrônica). 4 Conforme Resolução n 7.905, de 1996, da SEE/MG, indicada em Pires (2002). 
dos instrutores e dos administradores. No que concerne ao formato institucional, o Banco Mundial chega a recomendar a retirada das escolas técnico-profissionais do âmbito do Ministério da Educação de cada país e a sua vinculação ao setor privado.

No Estado de Minas Gerais, o Banco Mundial financiou um projeto na área gerencial, o "Programa de Qualidade Total na Educação" (PQTE), concebido com o apoio técnico da Fundação Christiano Ottoni (DORE SOARES, 1999). A iniciativa e o apoio do Banco Mundial para implementar suas estratégias de política educacional em Minas Gerais se sustentavam nos seguintes argumentos: foi o primeiro estado que implantou, simultaneamente, o ciclo básico, o programa de avaliação da escola pública, a eleição dos diretores pela comunidade escolar, a criação dos colegiados escolares e a autonomia escolar. Eram justamente as medidas tidas como resultado de um processo de democratização da educação em Minas Gerais que davam ao Banco Mundial os subsídios para aplicar suas propostas conservadoras.

Justamente no período de 1996 a 1997, quando se iniciou o processo de extinção das habilitações profissionais na rede estadual de Minas Gerais, a professora Rosemary Dore coordenava uma pesquisa, intitulada "Análise Prospectiva da Formação Profissional: o caso de Minas Gerais", realizada por professores e pesquisadores de instituições integrantes do Núcleo de Estudos e Pesquisas sobre Formação Profissional em Minas Gerais (NEFOR-MG)

Naquela época, de acordo com os dados da referida pesquisa, Minas Gerais tinha 1.852 escolas de ensino médio (profissionalizante e propedêutico), compreendendo todas as redes existentes, na esfera pública e privada (ver TAB. 1$)^{6}$.

5 As instituições participantes do NEFOR-MG eram: Universidade Federal de Minas Gerais (UFMG), Universidade do Estado de Minas Gerais (UEMG), Pontifícia Universidade Católica de Minas Gerais (PUC/MG), Universidade Federal de Lavras (UFLA), Universidade Federal de Juiz de Fora (UFJF) e a Fundação de Educação para o Trabalho de Minas Gerais (UTRAMIG). Essa pesquisa ganhou prêmio de Educação Profissional do Serviço Nacional de Aprendizagem Comercial (SENAC) em 2000.

6 As Tabelas 1, 2, 4 e 6 foram organizadas pela equipe de pesquisadores do NEFOR-MG (ver DORE SOARES, 1999), tendo como fonte de dados a SEE/MG e foi atualizada, em 2000, por Pires (2002). 


\section{TABELA 1}

Número total de estabelecimentos no ensino médio (profissionalizante e não profissionalizante), por dependência administrativa: 1986-2000

\begin{tabular}{l|r|r|r|r|r|r|r|r}
\hline Rede de ensino & $\mathbf{1 9 8 6}$ & $\mathbf{0}$ & $\mathbf{1 9 9 1}$ & $\mathbf{0}$ & $\mathbf{1 9 9 6}$ & $\mathbf{0}$ & $\mathbf{2 0 0 0}$ & $\mathbf{\%}$ \\
\hline Federal & 16 & 1,35 & 14 & 1,03 & 22 & 1,19 & 61 & 2,39 \\
Estadual & 522 & 44,16 & 811 & 59,85 & 1.203 & 64,96 & 1.532 & 60,05 \\
Municipal & 145 & 12,27 & 123 & 9,08 & 179 & 9,67 & 154 & 6,04 \\
Particular & 499 & 42,22 & 407 & 30,04 & 448 & 24,19 & 804 & 31,54 \\
Total & 1.182 & 100 & 1.355 & 100 & 1.852 & 100 & 2.551 & 100 \\
\hline
\end{tabular}

Fonte: "Análise Prospectiva da Formação Profissional: o caso de Minas Gerais", 1999, relatório técnico final.

No ano de 1996, a rede estadual se destacava na oferta do ensino profissional, possuindo um número de 183.649 matrículas, representando $69,56 \%$ do total de alunos matriculados nesse tipo de ensino. A rede particular de ensino, por sua vez, registrava um número de 37.892 alunos, representando $14,35 \%$ do total de matrículas no ensino profissionalizante em Minas Gerais (ver TAB. 2).

\section{TABELA 2}

Número de matrículas na educação profissional por dependência administrativa, em MG: 1986-2000

\begin{tabular}{l|r|r|r|r|r|r|r|r}
\hline Rede de ensino & $\mathbf{1 9 8 6}$ & $\mathbf{0}$ & $\mathbf{1 9 9 1}$ & $\mathbf{0}$ & $\mathbf{1 9 9 6}$ & $\mathbf{0}$ & $\mathbf{2 0 0 0}$ & $\mathbf{\%}$ \\
\hline Federal & 4.866 & 3,08 & 4.933 & 2,97 & 9.887 & 3,75 & 4.568 & 9,98 \\
Estadual & 74.120 & 46,95 & $\mathbf{1 0 4 . 7 1 7}$ & 62,95 & 183.649 & 69,56 & 10.149 & 22,18 \\
Municipal & 14.766 & 9,35 & 15.801 & 9,50 & 32.570 & 12,34 & 4.859 & 10,62 \\
Particular & 64.126 & 40,62 & 40.902 & 24,59 & 37.892 & 14,35 & 26.177 & 57,21 \\
Total & 157.856 & 100 & 166.353 & 100 & 263.998 & 100 & 45.753 & 100 \\
\hline
\end{tabular}

Fonte: "Análise Prospectiva da Formação Profissional: o caso de Minas Gerais", 1999, relatório técnico final.

A partir da reforma do ensino médio no Estado de Minas Gerais, ocorreu um expressivo aumento da participação da rede privada na oferta de ensino profissional. Tal crescimento, correspondendo a $82,60 \%$ de todas as escolas (rede estadual, rede municipal e rede federal), pode ser identificado com base nos dados do Instituto Nacional de Estudos e Pesquisas Educacionais Anísio Teixeira (INEP), referente ao ano de 2009 (ver TAB. 3). 


\section{TABELA 3}

Número de estabelecimentos de educação profissional por dependência administrativa, em MG: 2009

\begin{tabular}{l|c|r}
\hline Rede de ensino & $\mathbf{2 0 0 9}$ & \% \\
\hline Federal & 28 & 5,60 \\
Estadual & 27 & 5,40 \\
Municipal & 32 & 6,40 \\
Particular & 414 & 82,60 \\
Total & 501 & 100 \\
\hline
\end{tabular}

Fonte: INEP. Censo Escolar 2009. Sinopses Estatísticas.

Os dados do INEP sobre o número de estabelecimentos escolares de Minas Gerais em 2009, na esfera pública e privada, mostram que, enquanto as escolas públicas representam $17,4 \%$ do total da oferta de ensino profissional, as escolas da rede particular representam $82,60 \%$. Nesse quadro, o governo estadual é responsável por apenas $5,4 \%$ da oferta de formação profissional em nível médio.

Com referência ao número de alunos matriculados no ensino médio, os dados do INEP também permitem dizer que, em 1986, a maioria $(67,20 \%)$ frequentava escolas profissionalizantes. Contudo, a situação se inverte em 2009, pois a maioria dos alunos (87\%) passa a frequentar a escola de formação geral (ver TAB. 4 e 5). No ano de 2000, passa a predominar a formação geral, já que $95,39 \%$ dos alunos, portanto a maioria, frequentava escolas que não ofereciam nenhuma habilitação profissional (ver TAB. 4).

\section{TABELA 4}

Número de matrículas no ensino médio, por tipo de ensino, em Minas Gerais: 1986-2000

\begin{tabular}{l|c|c|c|c|c|c|c|r}
\hline Tipo de ensino & $\mathbf{1 9 8 6}$ & $\mathbf{0}$ & $\mathbf{1 9 9 1}$ & $\mathbf{0}$ & $\mathbf{1 9 9 6}$ & $\mathbf{0}$ & $\mathbf{2 0 0 0}$ & $\mathbf{\%}$ \\
\hline Sem habilitação & 77.060 & 32,80 & 118.674 & 41,64 & 309.660 & 53,98 & 947.256 & 95,39 \\
Profissionalizante & 157.856 & 67,20 & 166.353 & 58,36 & 263.998 & 46,02 & 45.753 & 4,61 \\
Total & 234.916 & 100 & 285.027 & 100 & 573.658 & 100 & 993.009 & 100 \\
\hline
\end{tabular}

Fonte: "Análise Prospectiva da Formação Profissional: o caso de Minas Gerais", 1999, relatório técnico final. 


\section{TABELA 5}

Número de matrículas no ensino médio, por tipo de ensino, em Minas Gerais em 2009

\begin{tabular}{l|r|r}
\hline Tipo de ensino & $\mathbf{2 0 0 9}$ & $\mathbf{\%}$ \\
\hline Sem habilitação & 716.146 & 87,00 \\
Profissionalizante & 107.318 & 13,00 \\
Total & 823.464 & 100 \\
\hline
\end{tabular}

Fonte: INEP. Censo Escolar 2009. Sinopses Estatísticas.

Já em 1996, os dados do relatório técnico final da pesquisa "Análise Prospectiva da Formação Profissional: o caso de Minas Gerais" (1999) mostram que o número de matrículas no ensino profissionalizante da rede estadual em Minas Gerais correspondia a 183.649 alunos, o que representava 69,56\% do total de matrículas (ver TAB. 6). Naquele ano, quando tem início a extinção dos cursos profissionalizante da rede estadual, esta se constituía na maior rede a oferecer esse tipo de ensino em Minas Gerais. Todavia, em 2009, o declínio da rede estadual na oferta de formação profissional é gritante, correspondendo a apenas 6,90\%, enquanto a rede particular se responsabiliza pela mais elevada oferta de ensino profissional, correspondendo a $76,85 \%$ da oferta dessa modalidade de formação no Estado de Minas Gerais (ver TAB. 7). Em seguida, com uma diferença bastante significativa, encontra-se a rede pública federal, representando apenas $12,08 \%$ da oferta de ensino profissional no estado.

TABELA 6

Número de matrículas na educação profissional por dependência administrativa, em MG: 1986-2000

\begin{tabular}{l|c|c|c|c|c|c|c|r}
\hline Rede de ensino & $\mathbf{1 9 8 6}$ & $\mathbf{0}$ & $\mathbf{1 9 9 1}$ & $\mathbf{0}$ & $\mathbf{1 9 9 6}$ & $\mathbf{0}$ & $\mathbf{2 0 0 0}$ & $\mathbf{\%}$ \\
\hline Federal & 4.866 & 3,08 & 4.933 & 2,97 & 9.887 & 3,75 & 4.568 & 9,98 \\
Estadual & 74.120 & 46,95 & 104.717 & 62,95 & 183.649 & 69,56 & 10.149 & 22,18 \\
Municipal & 14.766 & 9,35 & 15.801 & 9,50 & 32.570 & 12,34 & 4.859 & 10,62 \\
Particular & 64.126 & 40,62 & 40.902 & 24,59 & 37.892 & 14,35 & 26.177 & 57,21 \\
Total & 157.856 & 100 & 166.353 & 100 & 263.998 & 100 & 45.753 & 100 \\
\hline
\end{tabular}

Fonte: “Análise Prospectiva da Formação Profissional: o caso de Minas Gerais", 1999, relatório técnico final. 
TABELA 7

Número de matrículas na educação profissional por dependência administrativa, em MG: 2009

\begin{tabular}{l|c|r}
\hline Rede de ensino & $\mathbf{2 0 0 9}$ & $\mathbf{\%}$ \\
\hline Federal & 12.971 & 12,08 \\
Estadual & 7.408 & 6,90 \\
Municipal & 4.471 & 4,17 \\
Particular & 82.468 & 76,85 \\
Total & 107.318 & 100 \\
\hline
\end{tabular}

Fonte: INEP. Censo Escolar 2009. Sinopses Estatísticas.

Também em 2009, de acordo com os dados do INEP (2009), a maioria dos alunos matriculados na educação profissional, em Minas Gerais, estava na faixa de 20 a 24 anos, correspondendo a um total de 40.222 alunos (ver TAB. 8). Já aqueles que deveriam cursar essa modalidade de ensino na idade regular, entre 15 e 17 anos, representavam somente 9.317 alunos. Dessa forma, quem cursa o ensino profissionalizante atualmente é, predominantemente, o jovem maduro e que já passou pelo ensino médio de formação geral.

\section{TABELA 8}

Número de alunos da educação profissional por faixa etária, em Minas Gerais: 2009

\begin{tabular}{l|c|c|c|c|c|c|r}
\hline Total & 0 a 14 & 15 a 17 & 18 e 19 & 20 a 24 & 25 a 29 & 30 a 39 & Mais de 39 \\
\hline 106.701 & 69 & 9.317 & 19.527 & 40.222 & 19.446 & 13.206 & 4.914 \\
\hline
\end{tabular}

Fonte: INEP. Censo Escolar 2009. Sinopses Estatísticas.

A extinção da educação profissionalizante nas escolas estaduais pelo governo de Minas Gerais, entre 1996 e 1998, levou à situação atual, na qual é insignificante a oferta de formação profissional na rede pública, principalmente quando comparada à rede particular.

Assim, tendo destruído as possibilidades de formação profissional na rede estadual, o governo de Minas Gerais decidiu, a partir de 
2007, criar o Programa de Educação Profissional do Estado de Minas Gerais (PEP-MG). Por meio desse programa, passou a comprar vagas das escolas particulares de ensino profissional para oferecê-las aos estudantes da rede pública estadual e também aos concluintes da rede particular ou municipal.

Com essa política pública do governo de Minas Gerais, consolida-se a transferência da competência da oferta do ensino médio profissional do setor público estadual para o setor privado. O governo estadual passa a contratar a escola técnica privada para um serviço temporário e não assume o seu papel de manter escolas públicas para essa modalidade de ensino. O PEP-MG oferece curso e material gratuito aos estudantes das escolas públicas estaduais. Entretanto, mesmo que os alunos disponham dos recursos oferecidos pelo governo para realizar sua formação profissional, é elevada a quantidade daqueles que abandonam os cursos profissionalizantes.

\section{O Programa de Educação Profissional de Minas Gerais e a evasão escolar}

Com o Programa de Educação Profissional, o governo de Minas Gerais estabeleceu a meta de qualificar profissionalmente, no período de 2007 a 2010, cerca de 110 mil jovens que frequentam o $2^{\circ}$ e $3^{\circ}$ anos do ensino médio das escolas estaduais, bem como jovens de 18 a 24 anos que já concluíram o ensino médio em qualquer rede ${ }^{7}$.

O governo compra vagas em escolas da rede privada de ensino profissionalizante e as oferece ao aluno melhor classificado em uma prova classificatória, realizada anualmente. $\mathrm{O}$ aluno não paga o seu curso nem o material didático requerido, pois o governo do Estado custeia sua formação, embora não forneça outro tipo de ajuda, tal como bolsa de estudo ou auxílio financeiro indireto. Podem participar do processo seletivo, para ingressar no PEP-MG, alunos regularmente matriculados no $2^{\circ}$ ou no $3^{\circ}$ ano do ensino médio de escolas públicas estaduais, alunos regularmente matriculados no $1^{\circ}$ ou no $2^{\circ}$ ano do

7 Esses dados são apresentados no sítio do PEP-MG. Disponível em: <www.educacao.mg.gov.br/ projetos/projetos-estruturador>. Acesso em: 20 abr. 2010. 
curso de Educação de Jovens e Adultos (EJA) de ensino médio, na modalidade presencial, e aqueles que já concluíram o ensino médio, em instituições públicas ou privadas, desde que não estejam cursando o ensino superior. Metade das vagas do PEP-MG é destinada somente aos alunos que estão cursando o ensino médio na rede pública estadual; a outra metade das vagas é disputada por alunos oriundos de escolas privadas ou que já concluíram o ensino médio em qualquer rede de ensino.

Os convênios estabelecidos entre o governo do Estado de Minas Gerais e as instituições de formação profissional se fundamentam em análises das propostas das escolas que desejam participar do PEP-MG e aceitam a sua regulamentação.

Nas instituições credenciadas pela SEE/MG (escolas particulares e do "sistema S" $^{8}$ ) o PEP-MG ofereceu, em 2008, 23 mil vagas para 67 diferentes cursos, em 72 municípios ${ }^{9}$. Na rede estadual, 81 escolas, pertencentes a 60 diferentes municípios do estado, passaram a oferecer 24 cursos profissionalizantes para 10.891 alunos, incluindo o curso normal, voltado para a educação infantil.

Não obstante as maiores facilidades oferecidas pelo governo do Estado de Minas Gerais para os jovens realizarem o curso de formação profissional, o abandono no PEP-MG tem se mostrado surpreendentemente elevado.

As informações sobre a evasão no $\mathrm{PEP}-\mathrm{MG}^{10}$ foram obtidas por meio de um sistema de monitoramento dos cursos, organizado pela SEE/ MG, no qual são listados 13 motivos a serem escolhidos pelos alunos para indicar as suas razões para abandonar a formação profissional (ver TAB. 9).

80 chamado "sistema S" refere-se ao ensino técnico de nível fundamental e médio profissionalizante, oferecido pelas seguintes autarquias: Serviço Social do Comércio (SESC), Serviço Nacional de Aprendizagem Industrial (SENAI) e Serviço Social da Indústria (SESI).

9 As referidas informações são apresentadas no sítio do PEP-MG. Disponível em: <https://www. educacao.mg.gov.br/projetos/projetos-estruturadores/417-programa-de-educacao-profissional-pep>. Acesso em: 20 abr. 2010.

10 No que diz respeito ao PEP, seus gestores convencionaram designar cada etapa do programa como PEP I, para o ano de 2008, PEP II para o ano de 2009, PEP III para o ano de 2010 e assim sucessivamente. Os dados aqui apresentados se relacionam ao PEP I. 
TABELA 9

Causas de evasão no Programa PEP 2008

\begin{tabular}{l|r}
\hline Causas do abandono (PEP) & $\mathbf{0}$ \\
\hline 1. Emprego & 36,56 \\
2. Desinteresse / Sem justificativa & 20,91 \\
3. Horário incompatível & 9,15 \\
4. Estudos & 8,91 \\
5. Ingresso no curso superior & 7,40 \\
6. Mudança de município & 4,23 \\
7. Saúde & 3,01 \\
8. Transporte & 2,95 \\
9. Gravidez & 1,85 \\
10. Achou muito difícil & 1,85 \\
11. Não se identificou com o curso & 1,75 \\
12. Filhos & 1,43 \\
\hline
\end{tabular}

Fonte: SUPERINTENDÊNCIA DE ENSINO MÉDIO E EDUCAÇÃO PROFISSIONAL, SEE/MG, 2010

As informações obtidas através do sistema de monitoramento mostram que, em relação ao ano de 2008 (PEP-MG), do qual participaram 72 municípios, houve um índice de evasão superior a 10\% nos cursos oferecidos em 25 cidades do Estado de Minas Gerais. Trata-se de um índice alto de abandono.

Avaliar se uma determinada taxa de evasão é alta ou não é algo complexo, pois o objetivo das organizações internacionais, voltadas à educação, bem como de pesquisadores do assunto, é o de que não exista evasão. No âmbito internacional, a União Europeia fixou, numa reunião realizada em Lisboa, em 2000, que, até o ano de 2010, a taxa média de abandono escolar precoce nos países componentes daquela organização não deveria ser mais de 10\% (Cf. EUROPEAN COUNCIL, 2004, p. 21). No que diz respeito ao Brasil, uma pesquisa realizada pela Fundação Getúlio Vargas (FGV), em 2009, indica que uma taxa de evasão acima de $17,8 \%$ poderia ser considerada alta, embora não apresente maiores detalhamentos sobre o uso desse parâmetro. Entretanto, tomando-se o valor de 10\% como índice aceitável e 17\% como elevada taxa de evasão, verifica-se que, em 11 municípios do Estado de Minas Gerais, os índices são ainda maiores do que aquele da pesquisa brasileira, apresentando 
uma taxa que varia entre 46,67 e 19,26\%, sendo que, em quatro deles, a taxa é até de até $15 \%$ de evasão (ver TAB. 10).

TABELA 10

Cidades com maior índice de evasão no programa PEP 2008

\begin{tabular}{l|r}
\hline MUNICÍPIO (PEP) & \% de evasão \\
\hline Carmo do Paranaíba & 46,67 \\
Santa Vitória & 29,82 \\
Santa Rita do Sapucaí & 27,49 \\
Araguari & 26,67 \\
Frutal & 25,76 \\
Matozinhos & 21,32 \\
Itaúna & 20,48 \\
Poços de Caldas & 19,75 \\
Cataguases & 19,67 \\
Vespasiano & 19,58 \\
Vazante & 19,26 \\
Paracatu & 17,39 \\
Caratinga & 17,14 \\
Teófilo Otoni & 15,25 \\
Belo Horizonte & 15,02 \\
\hline
\end{tabular}

Fonte: SUPERINTENDÊNCIA DE ENSINO MÉDIO E EDUCAÇÃO PROFISSIONAL, SEE/MG, 2010

Considerando o índice de 1,5\% como baixo e tomando-o como parâmetro do desempenho do PEP-MG, verifica-se que somente 15 municípios, dos 72 participantes desse programa, demonstraram, no ano de 2008, um baixo índice de evasão (ver TAB. 11).

TABELA 11

Cidades com menor índice de evasão no programa PEP 2008

\begin{tabular}{l|r}
\hline MUNICÍPIO (PEP) & \% de evasão \\
\hline Sete Lagoas & 1,15 \\
Águas Formosas & 0,95 \\
Ituiutaba & 0,86 \\
Arcos & 0,00 \\
Brumadinho & 0,00 \\
Cel. Fabriciano & 0,00 \\
\hline
\end{tabular}




\begin{tabular}{l|r}
\hline MUNICÍPIO (PEP) & \% de evasão \\
\hline Cons. Lafaiete & 0,00 \\
Coromandel & 0,00 \\
Diamantina & 0,00 \\
Oliveira & 0,00 \\
Pedra Azul & 0,00 \\
Santos Dumont & 0,00 \\
Timóteo & 0,00 \\
Três Corações & 0,00 \\
Três Marias & 0,00 \\
\hline
\end{tabular}

Fonte: SUPERINTENDÊNCIA DE ENSINO MÉDIO E EDUCAÇÃO PROFISSIONAL, SEE/MG, 2010.

As informações obtidas pela SEE-MG sobre a evasão do PEP-MG mostram que a principal razão apresentada pelos evadidos é a necessidade de emprego (36,56\%), seguida pelo desinteresse (20,91\%) e, depois, bem abaixo, encontram-se outros motivos, tais como horário incompatível, ingresso no curso superior, mudança de cidade. O aluno do PEP abandona o curso por duas razões principais: a) pela sobrevivência, ou seja, a necessidade imediata de trabalho; b) devido ao desinteresse em fazer um curso profissionalizante.

Os motivos para a evasão escolar, constantes do questionário aplicado pelo PEP-MG, não são muito precisos quanto a algumas alternativas para aferir as causas do abandono do aluno. Algumas opções são imprecisas, como se pode observar, por exemplo, na segunda opção mais indicada "Desinteresse/Sem justificativa", que corresponde a 20,91\%, não deixando claro o tipo de desinteresse ao qual o aluno se refere.

O estudo sobre o fenômeno da evasão escolar no ensino médio profissionalizante no Brasil, especialmente em Minas Gerais, ganha contornos de urgência, uma vez que se trata de um curso caro, para o qual têm sido canalizados investimentos muito altos. Sem concluir a formação profissional, o indivíduo também reduz suas chances de inserção de modo qualificado no mercado de trabalho.

Dramática também é a evasão escolar no ensino médio, como mostra a pesquisa da Fundação Getúlio Vargas (2009). Seus resultados indicam que a tendência de abandono da escola, no ano de 2006, foi de 17,8\%, 
considerando os jovens entre 15 a 17 anos, ocorrendo já no primeiro ano de estudos. Entre os principais motivos para a evasão escolar, a pesquisa menciona três fatores: não quer estudar ou falta interesse $(40,29 \%)$, necessidade de trabalhar $(27,09 \%)$ e falta de acesso à escola (10,89\%).

Com o objetivo de melhorar a qualidade do ensino médio nas escolas públicas do país, o Ministério da Educação elaborou o documento "Ensino Médio Inovador" (BRASIL, 2009), fixando diretrizes voltadas a: superar desigualdades de oportunidades educacionais, universalizar o acesso e a permanência dos adolescentes de 15 a 17 anos no ensino médio, consolidar a identidade do ensino médio, oferecer aprendizagem significativa para jovens e adultos, reconhecer a prioridade da interlocução com as culturas juvenis. De acordo com o mencionado documento, apenas $68 \%$ dos jovens brasileiros, entre 15 e 19 anos, que deveriam frequentar o ensino médio estavam na escola; desses, apenas 13,44\% estavam matriculados em cursos profissionalizantes em $2006^{11}$.

Já as informações apresentadas pelo Censo Escolar do Instituto Nacional de Estudos e Pesquisas Educacionais Anísio Teixeira (INEP) sobre a situação do ensino profissionalizante de nível médio no Brasil, nos anos de 2007 e 2008, mostram que a maioria dos alunos matriculados na educação profissional técnica, por faixa etária, está na idade entre 20 e 24 anos e representa $31,78 \%$ das matrículas nessa modalidade de ensino. Ainda conforme os dados do INEP (2007; 2008), houve um decréscimo no número de alunos matriculados no ensino médio no Brasil, nos anos de 2007 e de 2008: enquanto em 2007 o percentual de alunos representava 15,78\% (correspondendo a 8.369.369 alunos), em 2008 houve um declínio, passando para o percentual de 15,72\% (representado 8.366 .100 alunos).

Atualmente, não é tarefa simples definir, identificar e classificar a evasão escolar, pois, além de existir uma indeterminação sobre o conceito de evasão, há também outros obstáculos a serem superados. Eles se relacionam, por exemplo, à obtenção de dados sobre a evasão, aos períodos considerados pelos organismos que coletam informações sobre o problema, às metodologias para o seu estudo. Não bastassem essas limitações, há

11 Os dados constantes do documento "Ensino Médio Inovador" (BRASIL, 2009) apresentam estimativas baseadas na Pesquisa Nacional por Amostra de Domicílios (PNAD) do Instituto Brasileiro de Geografia e Estatística (IBGE), relativas ao ano de 2006. 
também a grande dificuldade de localizar jovens que abandonaram a escola e de conseguir que eles falem sobre o assunto, devido, muitas vezes, ao desconforto que a situação representa para eles. Buscando identificar as condições que levam ao abandono escolar no ensino médio, Schargel e Smink (2002) indicam que o National Center for Education Statistics (NCES), nos Estados Unidos, considera como evadido o aluno que, em relação ao ano letivo daquele país, que se inicia no mês de outubro:

a) Estava matriculado em uma escola em algum período do ano letivo anterior, mas que não se encontrava mais matriculado em 1 de outubro do ano letivo em curso, ou

b) Não estava matriculado em 1 de outubro do ano letivo anterior, embora devesse estar,

c) Não conclui o segundo grau nem um programa educacional aprovado pelo estado ou distrito,

d) Não atende qualquer das seguintes condições excludentes: - transferência para escola pública de outro distrito, para uma escola particular, ou para um programa educacional aprovado pelo estado ou distrito, - ausência temporária da escola por motivo de suspensão ou doença ou - morte (SCHARGEL; SMINK, 2002, p. 17).

Outros fatores relevantes a serem considerados no exame do problema da evasão escolar dizem respeito à complexidade e à variedade de situações que o permeiam e aos diversos tipos e fatores que sobre ele incidem. Entre eles, segundo Schargel e Smink (2002), encontram-se, por exemplo, o abandono "eventual" (aquele que abandona e depois de um período retorna), o abandono "situacional" (o aluno faz o curso, mas não o conclui e não recebe um certificado de segundo grau) e o abandono por "contemporaneidade" (refere-se ao conjunto de alunos que deixam o ensino médio ao longo de um período de formação).

Existem fatores que, para Schargel e Smink (2002), podem ser considerados como de maior incidência sobre a evasão escolar, como a necessidade de trabalho, a pobreza, a falta de formação básica de qualidade no ensino fundamental, a dificuldade de acesso à escola, o não gostar da escola, a violência, a gravidez, entre outros. Os referidos autores traçam um resumo dos três possíveis tipos de evadidos mais 
comuns e chegam à seguinte classificação: o primeiro tipo seria o dos "dissidentes", alunos prestes a abandonar ou que já abandonaram a escola; o segundo seria o dos "desinteressados", alunos que permanecem na escola, mas que perderam o interesse pelo aprendizado; e, finalmente, o dos "excluídos", que são aqueles suspensos ou expulsos das escolas.

\section{Considerações finais}

As políticas públicas propostas e executadas pelo governo do Estado de Minas Gerais, destinadas ao ensino profissional, mostram que, desde o ano de 1996, houve uma reversão de peso com respeito à oferta dessa modalidade de ensino. A tendência à privatização da oferta do ensino profissional de nível médio, expressa nos dados aqui apresentados, é muito clara. Eles mostram também que o governo do Estado de Minas Gerais não assume de forma integral sua responsabilidade em relação não apenas ao ensino profissional, como também em relação ao ensino médio em geral ${ }^{12}$, obrigação essa estabelecida pela Constituição Federal.

A transferência da responsabilidade da oferta do ensino médio do setor público para o privado indica também que o governo de Minas Gerais não tem respeitado as diretrizes legais para o ensino (Lei de Diretrizes e Bases da Educação LDB - 1996). Desde o ano de $2008^{13}$, a legislação educacional do país incorporou o ensino técnico profissional ao ensino médio, indicando que a habilitação ali oferecida poderá ser desenvolvida nos próprios estabelecimentos de ensino médio ou em cooperação com instituições especializadas. A compra de vagas, oferecida através do PEP-MG, não pode ser considerada uma ação de cooperação e sim uma transferência de responsabilidade.

Em 2009, a legislação que orienta nacionalmente a educação no país passou a ter uma nova redação, segundo a qual o ensino médio e o ensino fundamental têm a mesma importância ${ }^{14}$. Assim, a busca da

12 Ver Emenda Constitucional n. 14, de 1996.

13 Conforme os art. 36A, 36B, 36C e 36D da Seção IVA da LDB 9.394/1996, incluídos através da Lei 11.741 , de 16 de julho de 2008 .

14 Isso ocorre quando foi alterado o texto da LDB 9.394/1996, passando-se da "progressiva extensão da obrigatoriedade e gratuidade ao ensino médio" para "universalização do ensino médio gratuito". Ver Lei n. 12.061/2009, no título III, artigo $4^{\circ}$, inciso II. 
universalização do ensino não fica restrita somente ao ensino fundamental, mas vai mais além, abrangendo também o ensino médio. Considerando esses aspectos das diretivas educacionais do país, o governo de Minas Gerais deveria oferecer ensino médio a todos os jovens na faixa etária de 15 aos 18 anos, seja ou não profissional, em sua própria rede de ensino e não de forma eventual, como a que tem sido ofertada através do PEP-MG. Outro aspecto que evidencia a desatenção do governo com referência à educação profissional é a pouca cobertura de cidades que foram contempladas com o PEP-MG em 2008, limitando-se a apenas 72 municípios, num total de 853 de cidades em todo o Estado de Minas Gerais.

A política educacional do Governo de Minas Gerais tem dado prioridade ao setor privado, o que vem ocorrendo nitidamente desde 1996, quando foi extinta a formação profissional nas escolas públicas. A nova política de formação profissional, aqui examinada, também privilegia a aplicação de recursos públicos no setor privado, beneficiando as escolas profissionalizantes da rede particular e não respondendo adequadamente às exigências de qualificação profissional dos jovens mineiros, dado o elevado índice de evasão registrado no PEP-MG. 


\section{Referências}

BRASIL. Emenda Constitucional n. 14, de 12 de setembro de 1996. Modifica os arts. 34, 208, 211 e 212 da Constituição Federal e dá nova redação ao art. 60 do Ato das Disposições Constitucionais Transitórias. Brasília, 1996. Disponível em: <http:/ / portal.mec.gov. br/arquivos/pdf/e1496.pdf>. Acesso em: 04 nov. 2011.

. INSTITUTO NACIONAL DE ESTUDOS E PESQUISAS EDUCACIONAIS ANÍSIO TEIXEIRA (INEP). Sinopses estatísticas da educação básica. Brasília, 2007. Disponível em: <http:/ / portal.inep.gov. br/basica-censo-escolar-sinopse-sinopse>. Acesso em: 05 maio 2010.

. INSTITUTO NACIONAL DE ESTUDOS E PESQUISAS EDUCACIONAIS ANÍSIO TEIXEIRA (INEP). Sinopses estatísticas da educação básica. Brasília, 2008. Disponível em: <http:/ / portal.inep.gov. br/basica-censo-escolar-sinopse-sinopse>. Acesso em: 05 maio de 2010.

Ministério da Educação. Ensino Médio Inovador. Brasília, 2009. Disponível em: <http:/ / portal.mec.gov.br>. Acesso em: 27 maio 2009.

. Lei n. 9.394, de 20 de dezembro de 1996. Estabelece as diretrizes e bases da educação nacional. Brasília, 1996. Disponível em: <www.planalto.gov.br/ccivil_03/leis/L9394.htm> Acesso em: out. de 2011.

. Lei n. 12. 061, de 27 de outubro de 2009. Altera o inciso II do art. $4^{\circ}$ e o inciso VI do art. 10 da Lei n. 9.394, de 20 de dezembro de 1996, para assegurar o acesso de todos os interessados ao ensino médio público. Brasília, 2009. Disponível em: <http:/ /www.planalto. gov.br/ccivil_03/_Ato2007-2010/2008/Lei/L11741.htm>. Acesso em: 05 maio 2010.

CUNHA, L. A. Ensino médio e ensino técnico na América Latina: Brasil, Argentina e Chile. Cadernos de Pesquisa, n. 111, São Paulo, 2000. 
Disponível em: <http:/ / www.scielo.br/scielo.php?script=sci_arttext \&pid=S0100-15742000000300003 >. Acesso em: 22 out. 2009.

DORE SOARES, R. (Coord.). Análise Prospectiva da Formação Profissional: o caso de Minas Gerais. Belo Horizonte: FAPEMIG, 1999 (Relatório técnico final - impresso).

EUROPEAN COUNCIL. Achieving the Lisbon goal: the contribution of VET: Final report to the European Commission. 2004. Disponível em: <http://ec.europa.eu/education/policies/2010/studies/maastricht_ en.pdf>. Acesso em: 20 mar. 2008.

FUNDAÇÃO GETÚLIO VARGAS (FGV). O tempo de permanência na escola e as motivações dos sem-escola. Marcelo Côrtes Neri (Coord.). Rio de Janeiro: FGV/IBRE, CPS, 2009. Disponível em: <http:/ / www.fgv. br/cps/tpemotivos/>. Acesso em: 05 maio 2009.

MINAS GERAIS. SECRETARIA DE ESTADO DA EDUCAÇÃO DE MINAS GERAIS (SEE/MG). Portal da SEE/MG. Projeto Estruturador. O Programa de Educação Profissional, 2009. Disponível em: <https:// www.educacao.mg.gov.br/projetos/projetos-estruturadores/417programa-de-educacao-profissional-pep>. Acesso em: 20 abr. 2010.

. SECRETARIA DE ESTADO DA EDUCAÇÃO DE MINAS GERAIS (SEE/MG). SUBSECRETARIA DE DESENVOLVIMENTO DA EDUCAÇÃO BÁSICA SUPERINTENDÊNCIA DE ENSINO MÉDIO E PROFISSIONAL (SEMP/MG). Portal da SEE/MG. Programa de Educação Profissional, 2009. Disponível em: <https://www. educacao.mg.gov.br>. Acesso em: 20 abr. 2010.

. Uma análise sobre políticas públicas e educação profissional em Minas Gerais no período de 1995 a 2000. In: REUNIÃO ANUAL DA ANPED, 26., Poços de Caldas, 2003. Disponível em:<www.anped.org.br/ reunioes/26/trabalhos/raissapimentapires.rtf>. Acesso em: 15 maio 2010. 
SCHARGEL, F. P.; SMINK, J. Estratégias para auxiliar o problema de evasão escolar. Tradução de Luiz Frazão Filho. Rio de Janeiro: Dunya Ed., 2002. 


\title{
The Vocational Education Program of Minas Gerais and drop out: a preliminary study (2008-2010)
}

\begin{abstract}
This study presents a brief history of educational public policies adopted by the State of Minas Gerais, in recent decades, for vocational education. The paper tries to define and identify the issue of school dropout in order to better understand this education phenomenon. Subsequently, it is studied the Vocational Education Program of Minas Gerais (PEP-MG in Portuguese) introduced by the government of this state in 2007, which offers free seats for students from Minas Gerais who wish to follow vocational courses and are studying or have finished high school. To offer courses of PEP-MG, the state buys places in private schools and provides them to students who have passed in an exam organized by the state. The study presented here results from a preliminary analysis on the PEP I, the first year of the program conducted in 2008. Then it is shown, based on statistical data, the drop out occurred in the PEP I, indicating their main reasons.
\end{abstract}

Keywords: high school; vocational education; school dropout.

Recebido: $21 / 06 / 11$

Aprovado: 27/08/11 